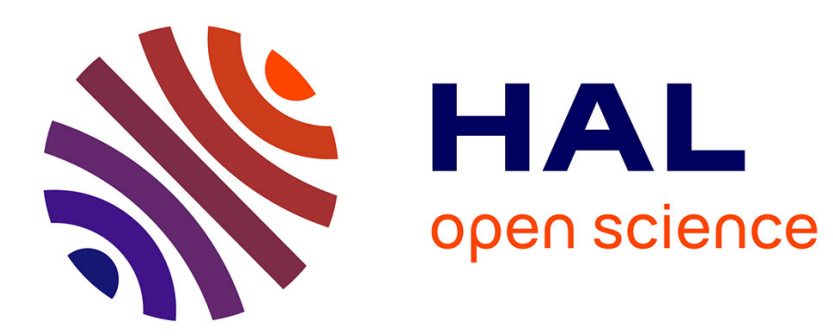

\title{
Testing the Hydromechanical Behavior of a Compacted Swelling Soil
}

\author{
Olivier Cuisinier, Farimah Masrouri
}

\section{To cite this version:}

Olivier Cuisinier, Farimah Masrouri. Testing the Hydromechanical Behavior of a Compacted Swelling Soil. Geotechnical Testing Journal, 2004, 27 (6), pp.598-606. 10.1520/GTJ11950 . hal-01768438

\section{HAL Id: hal-01768438 \\ https://hal.science/hal-01768438}

Submitted on 17 Apr 2018

HAL is a multi-disciplinary open access archive for the deposit and dissemination of scientific research documents, whether they are published or not. The documents may come from teaching and research institutions in France or abroad, or from public or private research centers.
L'archive ouverte pluridisciplinaire HAL, est destinée au dépôt et à la diffusion de documents scientifiques de niveau recherche, publiés ou non, émanant des établissements d'enseignement et de recherche français ou étrangers, des laboratoires publics ou privés. 


\title{
Testing the Hydromechanical Behavior of a Compacted Swelling Soil
}

\begin{abstract}
The paper presents a study of the hydromechanical behavior of a compacted swelling soil in a range of suctions comprised between 0 and around $300 \mathrm{MPa}$. To perform this study, two kinds of suction controlled oedometers were used, one using the osmotic method and the other using the salt solution method. A detailed review of the conditions for using these two methods is given in the first part of the paper. The second section provides the results of several suction controlled oedometer tests performed in this range of suction. They show that the mechanical behavior of the tested swelling material is strongly affected by the applied suction, even in the high suction range. In addition, it appeared that the samples preparation technique significantly influenced the hydromechanical behavior of the tested soil.
\end{abstract}

KEYWORDS: suction, swelling soil, salt solutions, osmotic method, hydromechanical behavior

\section{Introduction}

Compacted, clayey soils are widely used in geotechnical engineering for dam cores or to build barriers in waste landfill, and these types of materials are also considered for engineered barriers in nuclear waste storage facilities. In the latter case, the used materials contain a large amount of smectite, which is a highly swelling clay. On site, they can be submitted to complex suction/stress variations that could change dramatically their hydromechanical behavior, i.e., saturated and unsaturated mechanical behavior as well as their coupled behavior. Hence, understanding of the hydromechanical couplings in swelling materials is a key issue taking into account the applications for which they are intended. However, investigating experimentally, the hydromechanical behavior of unsaturated soils is a very difficult task when dealing with compacted swelling soils because of their low hydraulic conductivity and because their suction could fluctuate between 0 and several hundreds of $\mathrm{MPa}$. As a consequence, at least two suction control techniques, and hence, two kinds of suction controlled mechanical devices, are required to study their hydromechanical behavior. Between 0 and a low MPa number, two suction control methods are available. The first is the air overpressure technique (Richards 1935; Escario and Saez 1973). The second is the osmotic method (Zur 1966; Kassif and Ben Shalom 1971). For suctions higher than a few MPa, the only available method is the salt solutions technique. It was first used in an oedometer device by Esteban and Saez (1988) to control suction.

With these kinds of devices, several authors undertook the characterization of the behavior of several types of swelling soils. However, these studies were usually performed with only one kind of suction controlled oedometer. Consequently, when the osmotic or

Received May 12, 2003; Accepted for publication March 18, 2004; published November 2004.

${ }^{1}$ Post doctoral fellowship, Laboratoire Environnement Géomécanique \& Ouvrages-École Nationale Supérieure de Géologie, 54501 Nancy, France (formerly Soil Mechanics Laboratory - Swiss Federal Institute of Technology, 1015 Lausanne, Switzerland). E-mail: Olivier.Cuisinier@ensg.inpl-nancy.fr

${ }^{2}$ Professor, Laboratoire Environnement Géomécanique \& OuvragesÉcole Nationale Supérieure de Géologie, 54501 Nancy, France. Farimah. E-mail: Masrouri@ensg.inpl-nancy.fr the air overpressure method was used, the obtained results were limited to a suction range comprised between 0 and a low $\mathrm{MPa}$ number (e.g., Guiras-Skandaji 1996; Romero 1999; Alonso et al. 2001). Moreover, if the salt solutions method was used by itself, only the behavior for high suctions was well determined (Robinet et al. 1997; Al-Mukhtar et al. 1999). This is due to the fact that this method is unable to impose suctions between 0 and a low MPa number. In fact, only a few experimental programs were conducted with the combination of two kinds of suction controlled mechanical devices (Guillot et al. 2002; Lloret et al. 2003). Consequently, there is a lack of knowledge about the hydromechanical behavior of swelling soil over a wide suction range. As an example, Robinet et al. (1997) stated that the slope of the virgin compression line $\lambda(s)$ of a silty calcium bentonite is slightly influenced by the applied suction. This is in opposition to other results that highlighted a significant reduction of this parameter when suction increases (Guiras-Skandaji 1996) in a case of a pure calcium bentonite. There is a need to improve the knowledge about the influence of soil structure, of the degree of saturation and other parameters, to explain such behavior. Another point is the variation in preconsolidation stress with suction. This parameter is usually found to decrease significantly after a suction reduction (e.g., Romero 1999; Alonso et al. 2001), but little is known about the relationship between suction, swelling, structure, and preconsolidation stress.

In this context, the object of the study presented in this paper was to develop suction controlled oedometers in order to characterize the hydromechanical behavior of a swelling soil over a wide suction range. Two suction control methods were selected: salt solutions and osmotic. The first part of the paper presents some thoughts about the use of these methods for suction control. The suction range they can reach is then exposed. Some details about the experimental devices used in this study are also given. A first test series was conducted between 0 and around $300 \mathrm{MPa}$ to evaluate the variation in the apparent preconsolidation stress and the plastic compression line over this suction range. These data were supplemented by tests conducted on noncompacted samples in order to highlight the influence of the samples preparation technique. The final section of this paper outlines the main conclusions that can be inferred from these results. 

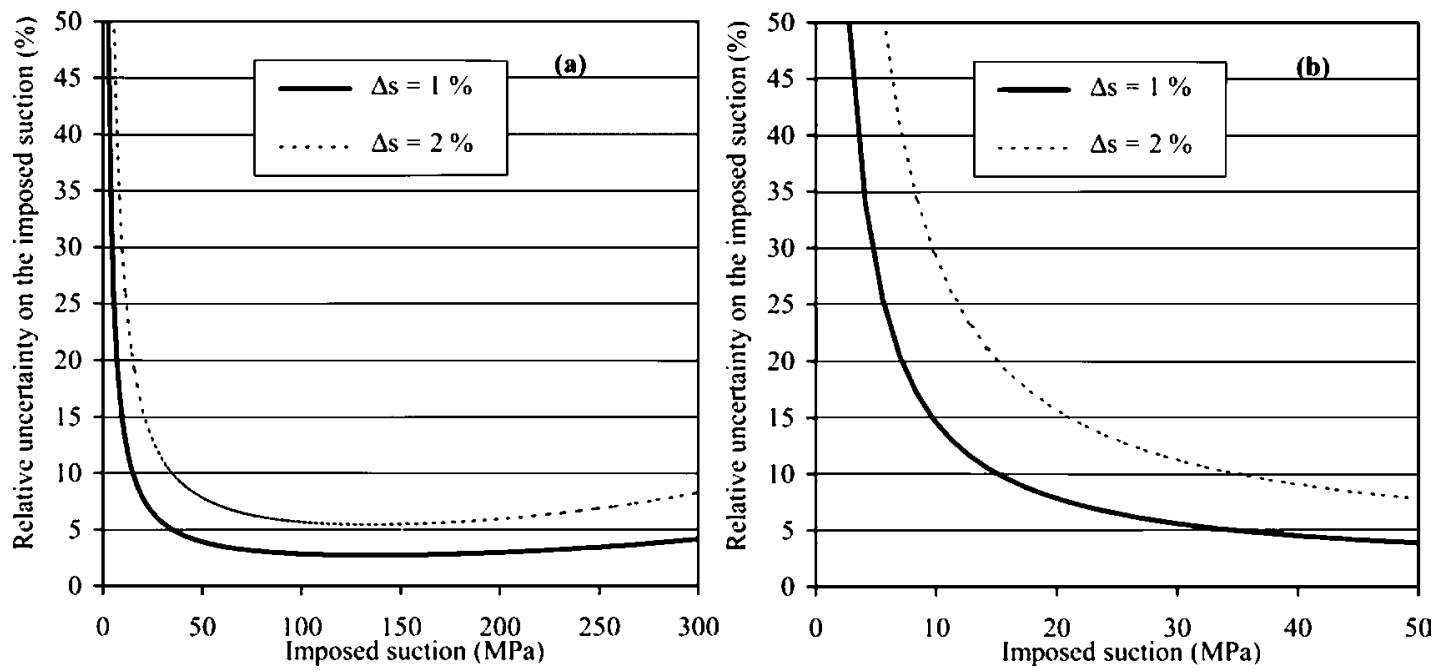

FIG. 1-Uncertainty about the imposed suction when using salt solutions: (a) large scale; (b) detail.

All the results will be given with respect to the net stress $\sigma^{*}=$ $\sigma-u_{a}$ and the suction $s=u_{a}-u_{w}$ in this paper. These two independent variables were defined using total stress $\sigma$, pore air pressure $u_{a}$, and pore water pressure $u_{w}$ (Coleman 1962; Fredlund and Morgenstern 1977).

\section{Salt Solutions Method}

\section{Basic Principle}

The basic principle of the saturated salt solution technique is to introduce a sample inside an airtight chamber where the relative humidity, $R H$, is maintained constant with a salt solution. The imposition of a given $R H$ to a soil sample allows its suction to be controlled considering Kelvin's Equation (Eq 1):

$$
s=-\gamma_{w} \frac{R T}{M g} \ln (R H)
$$

where $s=$ suction $(\mathrm{kPa}) ; R=$ constant of perfect gases $\left(8.31 \mathrm{~J}^{-1}\right.$. $\left.\mathrm{mol}^{-1} \cdot \mathrm{K}^{-1}\right), \gamma_{w}=$ unit weight of water $\left(9.81 \mathrm{kN} \cdot \mathrm{m}^{-3}\right), g=$ gravitational constant $\left(9.81 \mathrm{~m} \cdot \mathrm{s}^{-2}\right), M=$ molecular weight of water $\left(18 \cdot 10^{-3} \mathrm{~kg} \cdot \mathrm{mol}^{-1}\right)$, and $R H$ the relative humidity $(\%)$. It is possible to apply different suctions with this method, depending on the kind of salt solutions used and their concentration. In this study, totally saturated salt solutions were selected. It should be noted that this method imposes total suction.

\section{Uncertainty About the Imposed Suction}

The $R H$ value imposed by a given salt is available from different sources (Lide 2002; International Standard for Small Enclosures for Conditioning and Testing Using Aqueous Solutions to Maintain Relative Humidity at Constant Value, International Organization for Standardization Standard $n^{\circ} 483$; French Standard for Relative Humidity Measurements NF 15-119), and these values are given with an absolute uncertainty usually comprised between 0.5 and $1 \%$. However, between each source there could be some differences in the $R H$ value for the same salt. Considering this point, Delage et al. (1998) have shown that it is reasonable to assume that the uncertainty in $R H$ imposed by a given salt is comprised between 1 and $2 \%$. From these values it is possible to determine the relative uncertainty on the imposed suction using the following equation:

$$
\frac{\Delta s}{s}=-\gamma_{w} \frac{R T}{M g} \frac{\Delta R H}{R H}
$$

This function is represented in Fig. $1 a$. Below a suction of about $40 \mathrm{MPa}$, the relative uncertainty on the imposed suction increased dramatically. The suction zone comprised between 0 and $40 \mathrm{MPa}$ is plotted in Fig. 1b. This figure shows that below a suction of approximately $10 \mathrm{MPa}$, the relative uncertainty on the imposed suction went beyond 15 or $30 \%$. Therefore, the use of the salt solutions method should be restricted to suctions greater than 8$10 \mathrm{MPa}$ in order to limit uncertainties on the imposed suction. The $R H$ imposed by a given salt is also extremely sensitive to temperature, and the uncertainty values given previously are only valid if the temperature is at a constant value of $\pm 0.1{ }^{\circ} \mathrm{C}$.

Another element concerns the influence of the temperature and pressure homogeneity inside the testing device (Dueck et al. 2001). $R H$ corresponds to the ratio between the saturating vapor pressure of water $\left(p_{v s a t}\right)$ under given temperature and pressure and the actual vapor pressure $\left(p_{v}\right)$. Even when they are enclosed in the airtight cell, the pressure and temperature conditions between the salt solution and the soil sample could be different. Two cases are possible. The values near the solution will be named " 1 ", those near the soil sample will be " 2 ". First, suppose that $p_{v \text { sat }}$ is constant inside the chamber $\left(p_{v \operatorname{sat}(1)}=p_{v \operatorname{sat}(2)}\right)$, but that the vapor pressure is slightly different between the soil sample and the salt solution $\left(p_{v(1)} \neq p_{v(2)}\right)$. Hence, $R H_{2}$ near the soil sample is equal to:

$$
R H_{2}=R H_{1} \frac{p_{v(1)}}{p_{v(2)}}
$$

If we suppose that $p_{v}$ is constant inside the chamber $\left(p_{v(1)}=\right.$ $\left.p_{v(2)}\right)$, but that the saturating vapor pressure is slightly different between the soil sample and the salt solution $\left(p_{v \operatorname{sat}(1)} \neq p_{v \operatorname{sat}(1)}\right)$, $\mathrm{RH}_{2}$ near the soil sample is equal to:

$$
R H_{2}=R H_{1} \frac{p_{v \operatorname{sat}(1)}}{p_{v \operatorname{sat}(2)}}
$$

Consequently, the suction imposed on the soil sample could differ from the theoretically calculated, imposed suction. In addition, Table 1 gives an example of the imposed $R H$ as a function of the temperature difference between the salt solution and the air above the salt solution. This shows that a small temperature variation can 
TABLE $1-R H$ and imposed suction as a function of the temperature difference between the salt solution and the air of the chamber when the temperature of the salt solution is $20^{\circ} \mathrm{C}$.

\begin{tabular}{ccc}
\hline $\begin{array}{c}\text { Temperature Difference } \\
\text { Between Salt Solution and } \\
\text { Air of the Chamber, }{ }^{\circ} \mathrm{C}\end{array}$ & Chamber RH $^{\mathrm{a}}, \%$ & \\
\hline 0.3 & 76.9 & Imposed Suction $^{\mathrm{b}}, \mathrm{MPa}$ \\
0.2 & 76.4 & 35.4 \\
0.1 & 76.0 & 36.4 \\
0 & 75.5 & 37.1 \\
-0.1 & 75.0 & 38 \\
-0.2 & 74.6 & 38.9 \\
-0.3 & 74.1 & 39.6 \\
\hline
\end{tabular}

${ }^{\text {a }}$ Data from NF 15-119.

${ }^{\mathrm{b}}$ Calculated with Eq 1.

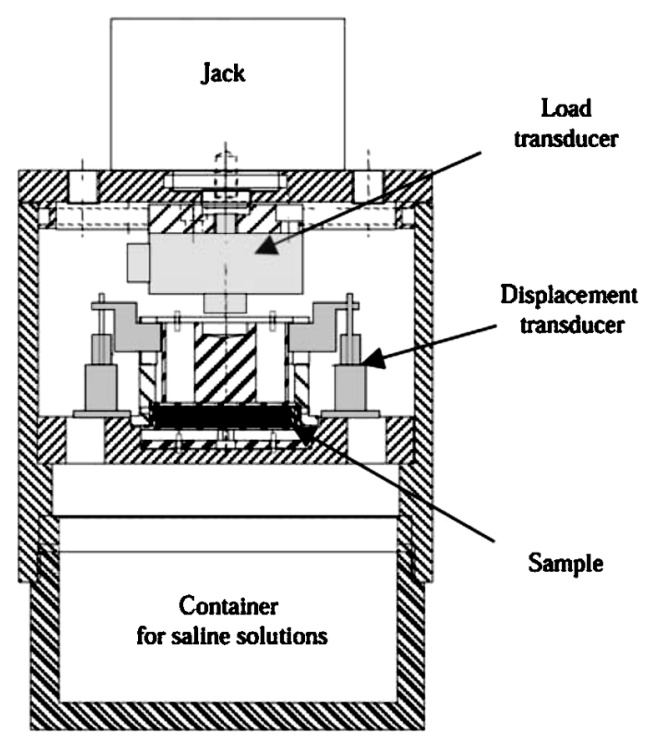

FIG. 2-Schematic of the new suction controlled oedometer with salt solutions.

have major consequences on the imposed suction. Therefore, it is essential to have the same temperature and pressure conditions near the soil sample and the salt solution to minimize uncertainties on the imposed suction.

\section{Presentation of the Salt Solutions Oedometer}

The developed oedometer device using saturated salt solutions is shown in Fig. 2. Within the same system, this device combines the functions of a basic oedometer and of a closed chamber with constant relative humidity (ISO 483). Based on this principle, two different devices with two maximum vertical stress capacities (1200 and $20000 \mathrm{kPa}$ ) were developed. The diameter of the sample was $7.4 \mathrm{~cm}$ in the low vertical stress oedometer and $5 \mathrm{~cm}$ in the other one. In both cases, the initial height of the sample was more or less $1 \mathrm{~cm}$. The different elements of the device in contact with the sample were made of porous steel in order to facilitate the vapor transfer between the sample and the saturated salt solution. During testing, each oedometer device was introduced inside a temperature insulated box in order to maintain its temperature at $20 \pm 0.15^{\circ} \mathrm{C}$ for the duration of each test. The use of a ventilator inside the oedometer to maintain a homogeneous temperature and pressure
TABLE 2-Characteristics of selected salts.

\begin{tabular}{lccc}
\hline \multicolumn{1}{c}{ Salt } & $\begin{array}{c}\text { Solubility }^{\mathrm{a}} \text {, g of } \\
\text { Salt per g of Water }\end{array}$ & $\mathrm{RH}, \%$ & $\begin{array}{c}\text { Imposed Suction } \\
\text { (bPa }\end{array}$ \\
\hline $\mathrm{LiCl}, \mathrm{x} \mathrm{H}_{2} \mathrm{O}$ & 827 & 12 & 287.9 \\
$\mathrm{MgCl}, 6 \mathrm{H}_{2} \mathrm{O}$ & 567 & 33 & 150.6 \\
$\mathrm{Mg}\left(\mathrm{NO}_{3}\right)_{2}, 6 \mathrm{H}_{2} \mathrm{O}$ & 689 & 54 & 83.6 \\
$\mathrm{NaCl}$ & 360 & 75 & 38.9 \\
$\mathrm{KCl}$ & 341 & 86 & 20.5 \\
$\mathrm{KNO}_{3}$ & 320 & 94 & 8.5 \\
\hline
\end{tabular}

${ }^{a}$ Values from Lide (2002) given for $20 \pm 0.1^{\circ} \mathrm{C}$.

${ }^{\mathrm{b}}$ Calculated with Eq 1.

conditions was abandoned, because it provoked an uncontrolled rise of temperature due to the motor heating. Following a change in the applied suction and/or the vertical stress, several weeks are required before the deformation equilibrium is reached. Therefore, one complete test might take several months. Table 2 shows the salt solutions that were selected for this study. Further details about the testing device are available in Cuisinier and Masrouri (2002).

\section{Osmotic Oedometer}

Basic Principle

In this method, a semi-permeable membrane is introduced between a solution of macromolecules and an unsaturated soil sample (Zur 1966). The exchange of water is due to the process of osmosis. The amount of exchanged water, and therefore the suction, is controlled by the macromolecule concentration: the higher the concentration, the higher the suction. In this method, only the matrix suction of the sample is mastered. The macromolecule commonly in use is the polyethylene glycol (PEG) with a molecular weight of 20000 or $6000 \mathrm{Da}$ (1 Dalton, $\mathrm{Da}=1.660510^{-24} \mathrm{~g}$ ). The relationship between PEG concentration and suction is independent of the PEG molecular weight (Williams and Shaykewich 1969). These two authors have provided the calibration curve for suctions ranging between 0 and around $1.5 \mathrm{Mpa}$, and it was extended as far as a suction of 8.5 MPa by Delage et al. (1998) and Cuisinier and Masrouri (2001). To fit these data, the following empirical calibration equation was proposed by Delage et al. (1998):

$$
s=11 c^{2}
$$

where $s$ is the suction and $c$ the concentration of the PEG solution expressed in $g$ of PEG per $g$ of water. The calibration curve and the empirical calibration curve are displayed together in Fig. 3. The temperature influences the relationship between PEG concentration and suction (Guiras-Skandaji 1996). In order to limit this effect, the temperature was maintained at $20 \pm 1.5^{\circ} \mathrm{C}$.

\section{Osmotic Oedometer}

The basic principle of the osmotic oedometer used in this study is presented in Fig. 4. A peristaltic pump circulated the macromolecules solution (PEG). The solution passes through the special base of the oedometer, which was designed to allow fluid to circulate all around the bottom of the sample. Between the sample and the PEG solution, a semipermeable membrane is introduced to prevent PEG macromolecules from passing toward the sample. In the device, the maximum vertical stress accessible was $1800 \mathrm{kPa}$. The range of suction was comprised between 0 and 8.5 MPa. The diameter of the sample was $7 \mathrm{~cm}$, and its initial height was about 


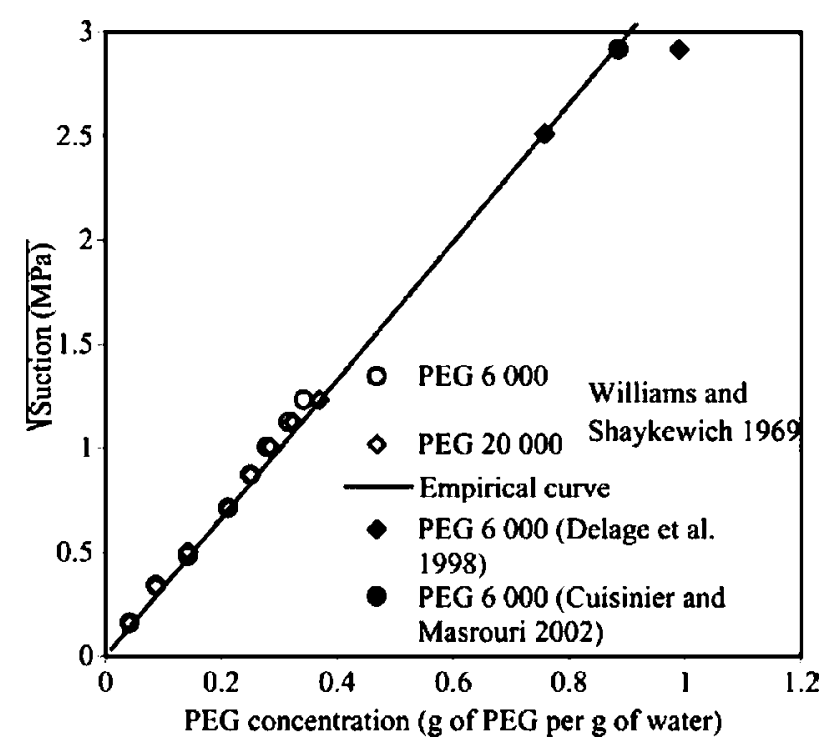

FIG. 3-Calibration curve of PEG.

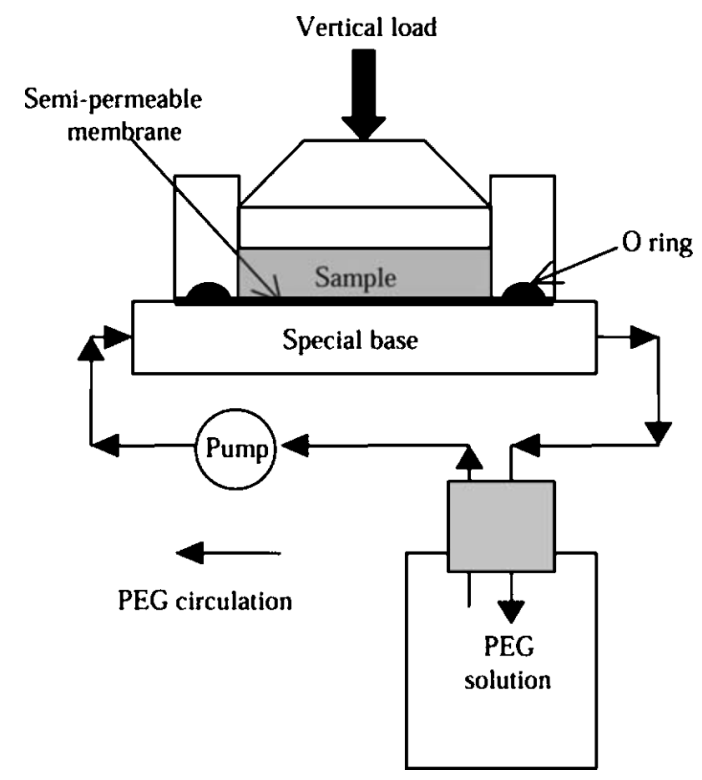

FIG. 4-Schematic of the osmotic device.

$1 \mathrm{~cm}$. When a given suction was applied, approximately 10 days were needed for deformation equilibrium to be reached. Mechanical loading was performed in the same manner as in a typical oedometer test, and approximately 2 days were needed to reach deformation equilibrium for a given stress step.

\section{Studied Material and Sample Preparation}

The studied material was made of $40 \%$ silt and $60 \%$ of a commercially available bentonite. The mineralogical composition of these materials was determined by X-ray diffractometry. The silt contains $60 \%$ quartz, $20 \%$ montmorillonite, and $11 \%$ feldspar, with the remaining part containing kaolinite and mica. The bentonite contains more than $80 \%$ calcium montmorillonite. The liquid limit of the mixture was $87 \%$, and its plastic index was $21 \%$.

The two materials were mixed together and wetted to a mass water content of $15 \%$. The wet mixture was then sealed in an airtight container and left for at least ten days to reach moisture equilibration inside the mixture. After this period, the mixture was statically compacted under a vertical stress of $1 \mathrm{MPa}$, directly inside the oedometer device. This low water content enabled shrinkage to be limited when the sample was dried in the oedometer. It was not possible to prepare samples with a mass water content under $15 \%$, because in this case samples were not strong enough to work with. The initial dry density was $12.7 \pm 0.1 \mathrm{kN} \cdot \mathrm{m}^{-3}$ for all tested samples. The initial matrix suction, measured by the filter paper technique in accordance with ASTM Test Method for Measurement of Soil Potential (Suction) Using Filter Paper (D 5298), was comprised between 20 and $25 \mathrm{MPa}$. Under these conditions, the swelling potential and the swelling pressure, measured with the free swelling technique in accordance with ASTM Test Method for One-Dimensional Swell or Settlement Potential of Cohesive Soils (D 5298), were respectively $19 \%$ and $0.25 \mathrm{MPa}$.

\section{Experimental Results on Compacted Samples}

The stress paths followed and the compression curves obtained are given in this section. The variation in the degree of saturation and the water content is presented and discussed, considering the structure of the samples at the different stages of the tests. Subsequently, the mechanical parameters are exposed and commented on. In a final discussion, a comprehensive interpretation of hydraulic and mechanical data obtained during all tests performed on compacted samples is proposed.

\section{Stress Paths}

All the stress paths of the tests were divided into two steps. A given suction was applied in several stages, and then the samples were mechanically loaded under a constant suction. All the stress paths are described in Fig. 5 and in Table 3. The Test OWL6 was not represented in Fig. 5, because the applied suction was null (saturated sample). In Fig. 5 and the following figures, the vertical net stress $\sigma_{v}^{*}$ is used to plot the data.

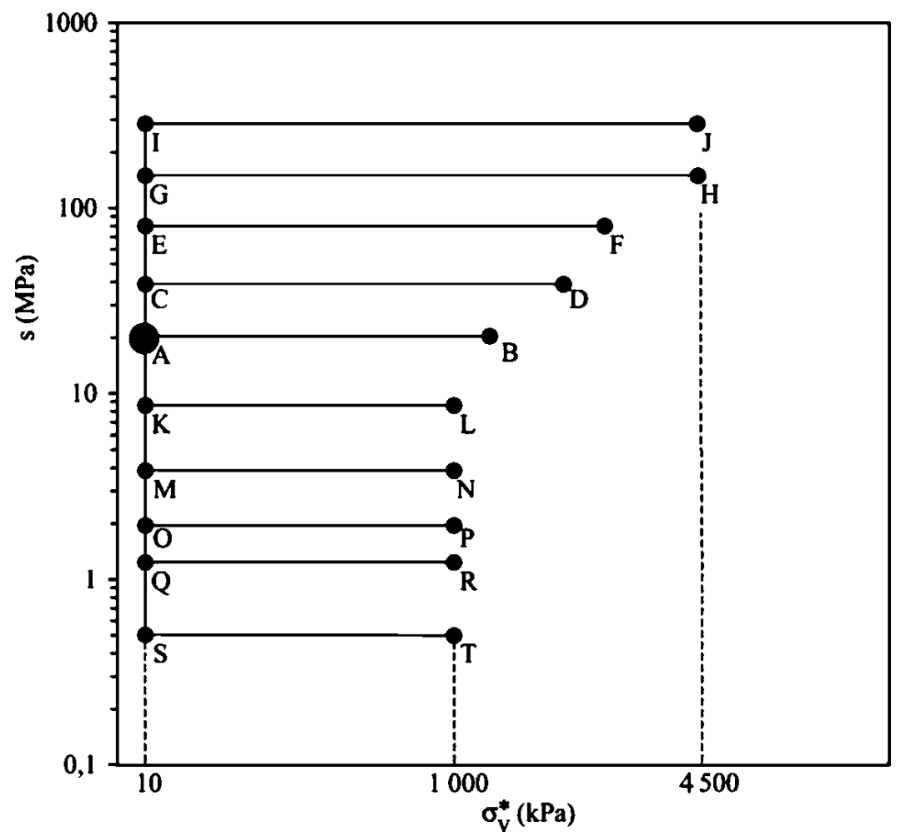
ples) 
TABLE 3-Details of the followed stress paths (cf. Fig. 5).

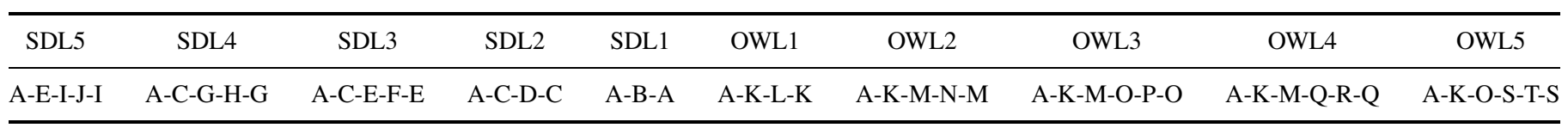

TABLE 4-Swelling/shrinkage during the suction change phase under low vertical stress.

\begin{tabular}{lccccccccccc}
\hline & SDL5 & SDL4 & SDL3 & SDL2 & SDL1 & OWL1 & OWL2 & OWL3 & OWL4 & OWL5 & OWL6 \\
\hline Applied suction (MPa) $^{287.9}$ & 150.6 & 83.6 & 38.9 & 20.5 & 8.5 & 4 & 2 & 1.2 & 0.5 & 0 \\
Swelling $^{\mathrm{a}}(\%)$ & -2.7 & -2.1 & -1.7 & -0.4 & 0 & 1.2 & 3.9 & 4.5 & 9.5 & 10.4 & 18.2 \\
\hline
\end{tabular}

${ }^{a}$ Negative values indicate a sample shrinkage.
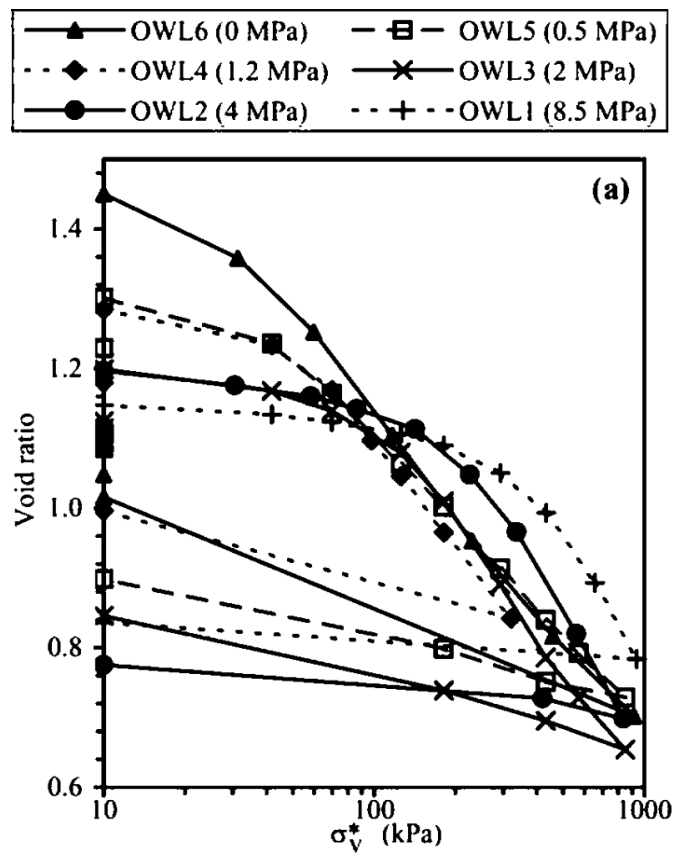
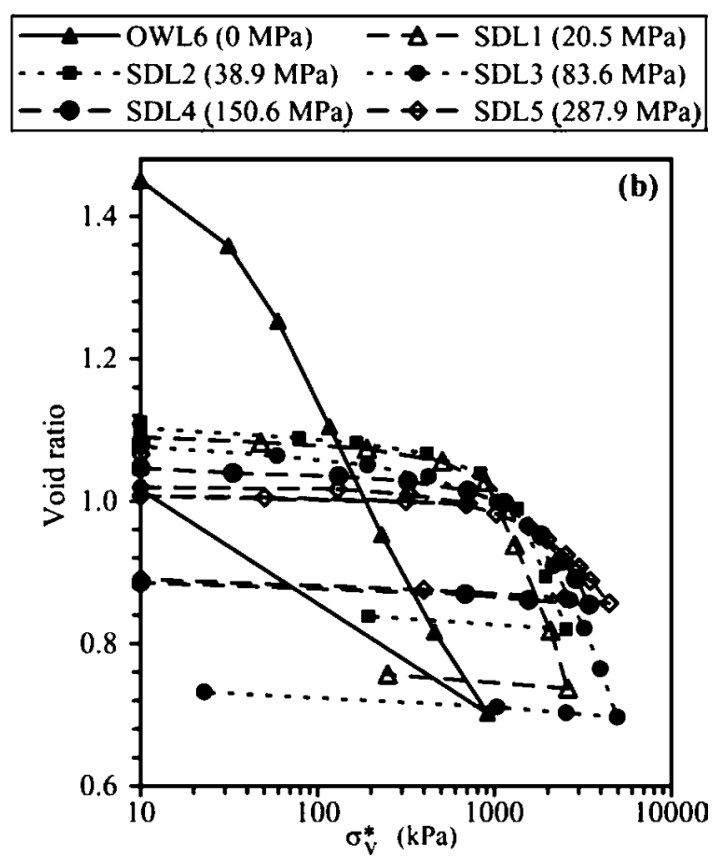

FIG. 6-Oedometer tests results: (a) applied suction lower than 4 MPa; (b) applied suction higher than 4 MPa and Test OWL6.

In the case of osmotic tests (Tests OWL1-OWL6), the maximum $\sigma_{v}^{*}$ was similar in each test. In the tests performed with a salt solutions oedometer (Tests SDL1-SDL5), the maximum $\sigma_{v}^{*}$ was different in each test. These samples were unloaded as soon as the slope of the plastic part of the curve was able to be determined in order to limit the duration of the test. In the case of Test SDL5applied suction of $287.9 \mathrm{MPa}$ - the sample was loaded up to a net vertical stress of $5000 \mathrm{kPa}$, and due to an experimental problem related to the pressure supply system, was then unloaded. Finally, it was loaded up to $2500 \mathrm{kPa}$. In Test OWL4, the data acquisition system failed during the test and the data are not complete.

The initial void ratio of all samples after their preparation was about 1.10. The imposed suction change under low vertical stress provoked a modification of the void ratio (Table 4). After this phase, the samples were mechanically loaded under constant suction. The obtained oedometric curves are plotted in Fig. $6 a$ and $6 b$. In both figures the Test OWL6 (saturated sample) is also reported.

Two kinds of behavior were observed as a function of the applied suction. For suctions lower than $4 \mathrm{MPa}$ (Fig. 6a), the suction reduction phase provoked a significant void ratio increase: the lower the suction, the higher the swelling. However, despite very different initial void ratios, all these curves tend to join the OWL6 oedomet- ric curve during the mechanical loading. Conversely, in the case of applied suctions higher than $4 \mathrm{MPa}$ (Fig. 6b), the suction reduction phase led to a slight modification of the void ratio. Consequently, the void ratios at the beginning of the mechanical loading were quite similar for all these tests. During the mechanical loading, these curves tend to cross the OWL6 curve without joining it under high vertical stresses. It should be remarked that the case of the OWL2 test (Fig. 6a), applied suction of $4 \mathrm{MPa}$, was intermediate between the two previous groups in the sense that it crossed the OWL6 curve and joined it from an applied stress of about $550 \mathrm{kPa}$.

\section{Saturation Degree (S) and Mass Water Content $(w)$}

The saturation degree and the mass water content of the samples were determined at the different stages of the tests: initial state, after the suction change phase under low vertical stress inside the oedometer, and after the loading/unloading under constant suction phase. The initial conditions were identical in all tests $(S=37 \%$ and $w=15 \%$ ). It was not possible, with the devices used, to monitor the volume of exchanged water during the suction change under low stress phase. To overcome this problem, the saturation degree and the mass water content of the samples before the mechanical 

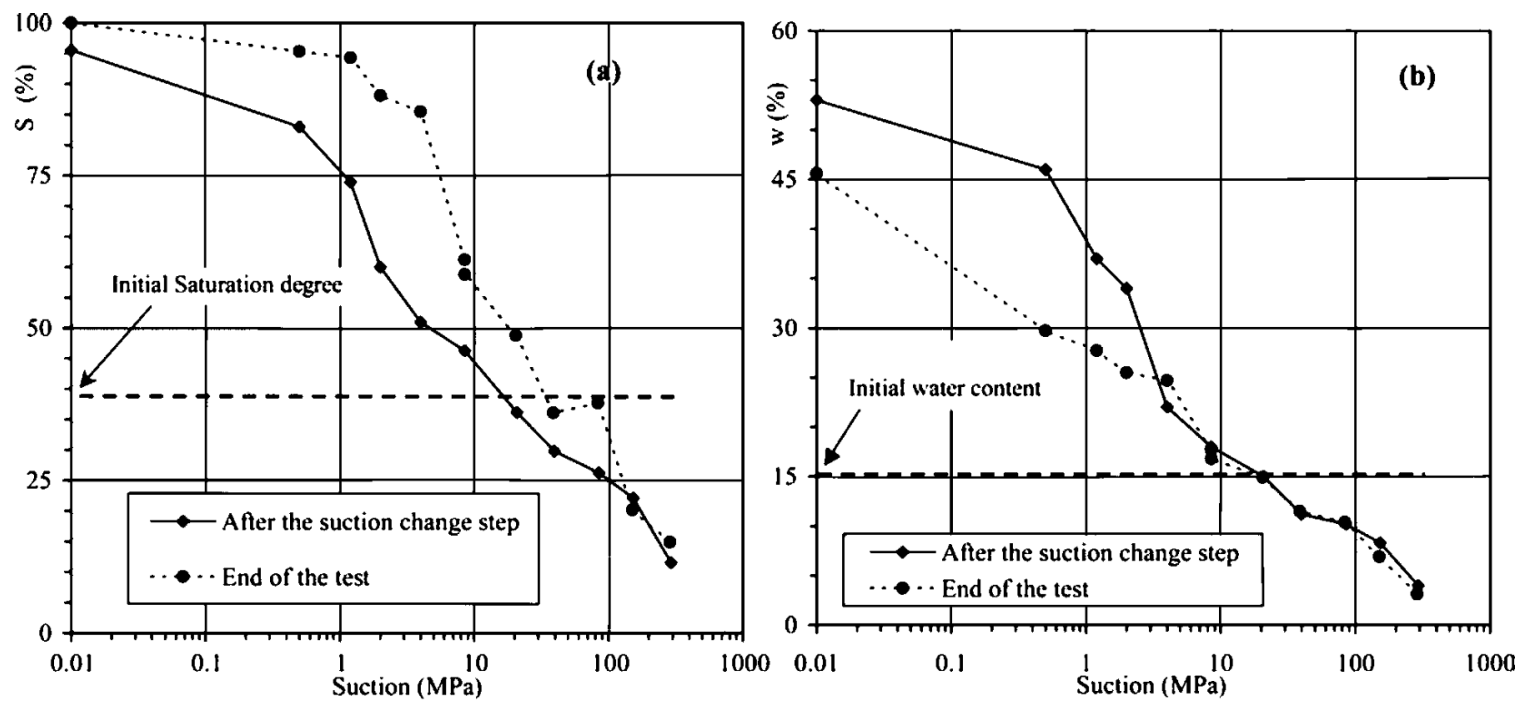

FIG. 7-Saturation degree (a) and mass water content (b) variation during each test.

loading under constant suction were estimated from the retention curve of the tested samples (Cuisinier 2002). The final $S$ and $w$ values, after the loading/unloading phase, were determined with standard procedures (Fig. $7 a$ and $7 b$ ).

Figure 7 shows the existence of two different behaviors as a function of the applied suction. In the case of an applied suction lower than $4 \mathrm{MPa}$, the mechanical loading prompted a significant increase of $S$ and an important decrease of $w$. The final $S$ was close to full saturation at the end of those tests (higher than $85 \%$ ). It should be noted that the final value of $S$ is also related to the maximum imposed vertical stress. Hence, it is more difficult to interpret the final $S$ data obtained for applied suctions higher than $4 \mathrm{MPa}$, as the maximum vertical stress was different in these tests. The important point is that the mechanical loading did not affect the mass water content of the samples.

These results could be interpreted considering the internal structure of the soil samples prior to loading. It has been shown in a previous study (Cuisinier 2002) that tested samples exhibited a clear double structure with micro and macropores above a suction of $4 \mathrm{MPa}$. Below this suction value, the internal structure of the samples was homogenous. It is well known that in the case of soils having a double structure, mechanical loading produces a progressive reduction in macropore volume. The aggregates themselves are very slightly affected by mechanical loading (Delage and Lefebvre 1984; Griffiths and Joshi 1989; Qi et al. 1996). In the range of suctions above $4 \mathrm{MPa}$, the water was essentially located inside the aggregates, and the pores between aggregates could be considered as empty of water. In addition, the water is strongly bonded to the soil water particles in this range of suction (Komine and Ogata 1992; Yong 1999). These observations could explain that the water content was not affected by mechanical loading. The situation was different when the internal structure of the samples was homogeneous (applied suctions lower than $4 \mathrm{MPa}$ ). Inside these samples, water surrounded the soil particles and partly filled the voids. In addition, water is less bonded to clay particles when suction is lower than $4 \mathrm{MPa}$. During the loading process, the void between the particles is reduced in size. As the imposed suction was maintained constant by the suction control system, water was expelled by the soil sample. This phenomenon could explain the decrease of $w$ and the increase of $S$ in these tests.

\section{Mechanical Parameters}

In order to complete the previous results, the mechanical parameters were determined in each test. These are the elastic and the plastic compression slopes of the oedometric curve, respectively $\kappa$ and $\lambda(s)$, and the apparent preconsolidation stress, $p_{0}(s)$ (Fig. $8 a$ and $b)$.

Figure $8 a$ shows first that the value of $\kappa$ decreased as suction increased. However, the variations in this parameter were relatively small, and consequently, it could be considered that $\kappa$ is constant for the tested material. The variation of $\lambda(s)$ with the applied suction was not monotonous as seen in Fig. 8a. The values of $\lambda(s)$ were constant between 0 and approximately $4 \mathrm{MPa}$. They reached a maximum under a suction of $4 \mathrm{MPa}$. Beyond $8.5 \mathrm{MPa}$, increasing suctions tend to decrease the values of $\lambda(s)$. The preconsolidation stress could be considered constant for suctions above 83.6 MPa. However, the $p_{0}(s)$ determined under null suction is very low compared to the initial stress $p_{0}(s)$ of the samples $(1000 \mathrm{kPa})$. This could be related to the high swelling during the suction imposition phase (Fig. 8b).

The majority of the results available in the literature agree with the conclusion that $\kappa$ is constant with suction (e.g., Alonso et al. 1990). The observations about the $\lambda(s)$ variation with suction are different from those found in the literature concerning the relations between parameter $\lambda(s)$ and suction. In a majority of cases, $\lambda(s)$ decreases monotonously when suction is increased (e.g., Alonso et al. 1990). There are also a few results in agreement with our results (Wheeler and Sivakumar 1995; Geiser 1999).

\section{Discussion}

The obtained results showed that the suction of $4 \mathrm{MPa}$ was associated with a significant modification in the hydromechanical behavior of the tested samples. Above $4 \mathrm{MPa}$, the samples had a double structure, the water content was constant during the mechanical loading under constant suction, and the values of $\lambda(s)$ decreased with the suction increase. Below $4 \mathrm{MPa}$, the samples had a homogenous structure, mechanical loading under constant suction caused water to depart, and the values of $\lambda(s)$ were constant. The results obtained for a suction of $4 \mathrm{MPa}$ were intermediate between these 

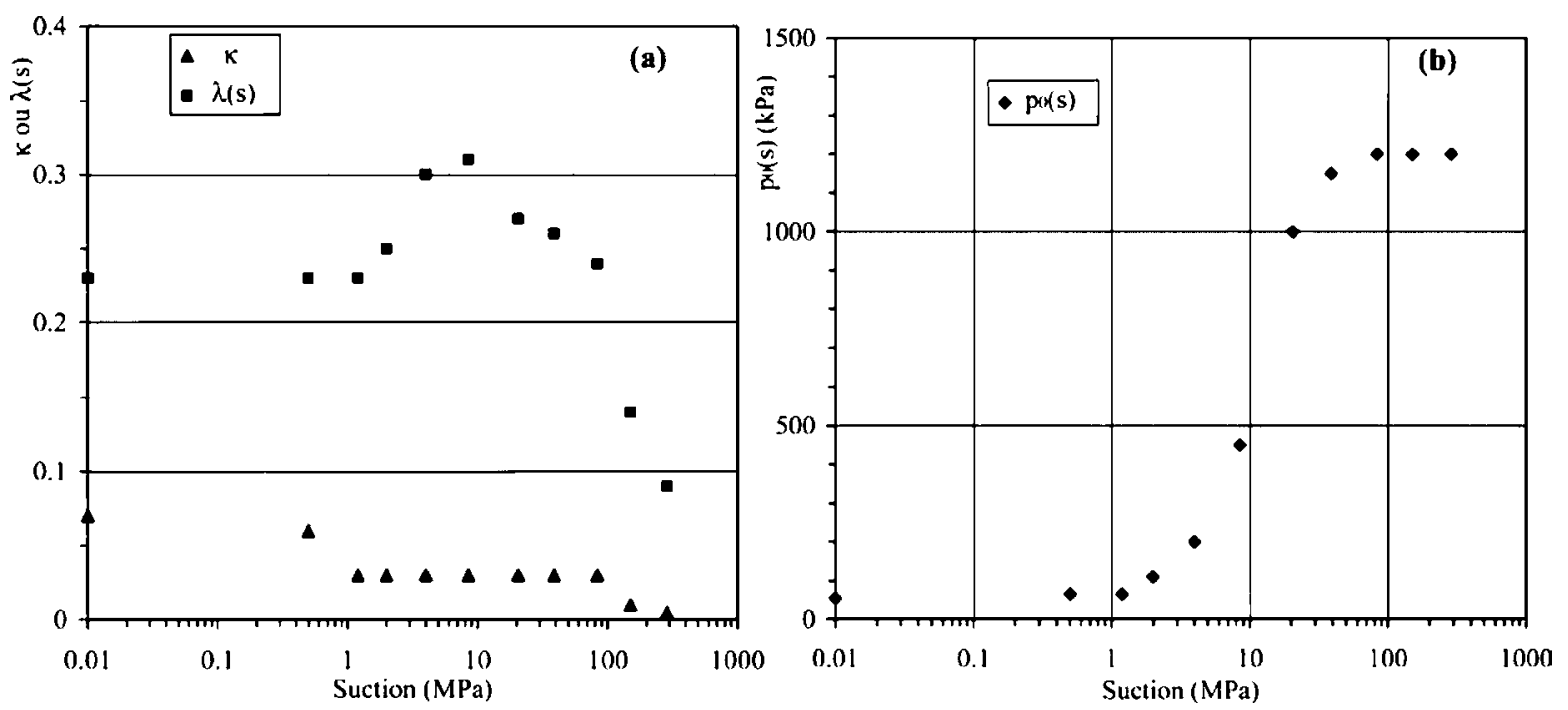

FIG. 8-Mechanical parameters as a function of applied suction: (a) elastic and plastic slope of compression curves; (b) apparent preconsolidation stress.

two kinds of behavior. Consequently, the change of internal structure seemed to be associated with a change in the hydromechanical behavior of the tested material.

This conclusion is supported by existing results in the literature. The influence of the internal structure of a soil sample on its hydromechanical behavior was highlighted by Sivakumar and Wheeler (2000). These authors have determined the relationship between $\lambda(s)$ and the applied suction for kaolin statically compacted to two different vertical stresses (400 and $800 \mathrm{kPa}$ ). They have shown that the compressibility of the less compacted samples reaches a maximum value under a suction of $100 \mathrm{kPa}$. In the case of the more compacted samples, they observed a continuous decrease of $\lambda(s)$ as the suction was increased from 0 up to $300 \mathrm{kPa}$. They explained that this is the mark of the influence of the initial, internal structure of the material on its mechanical behavior as the internal structure of the material changes from a double-structure fabric to a more uniform fabric as the compaction energy is increased.

\section{Influence of the Samples Preparation Procedure on Mechanical Behavior}

In this section, the testing procedure followed in order to study the influence of the sample preparation technique is exposed. Then, these additional results are presented and discussed considering the structure of each kind of sample.

\section{Testing Procedure}

Two tests were conducted on the material in the form of powder to evaluate the influence of the preparation procedure on mechanical behavior. To prepare the samples for the "powder tests," two dessicators were used. In each device, $100 \mathrm{~g}$ of dry material were introduced. In the first one, the imposed suction was closed to the initial suction of the samples (20.5 MPa), and in the other the imposed suction was 287.9 MPa (Test SP2). A suction controlled compression test was then conducted on each powder. Test $\mathrm{R}$ was conducted on the mixture prepared at a mass water content of 1.5 (the liquid limit). Then the compression test was performed inside an oedometer. The imposed suction was $0 \mathrm{MPa}$. The results of these tests are plotted in Figs. 9, 10, and 11. Test $\mathrm{R}$ was compared to Test

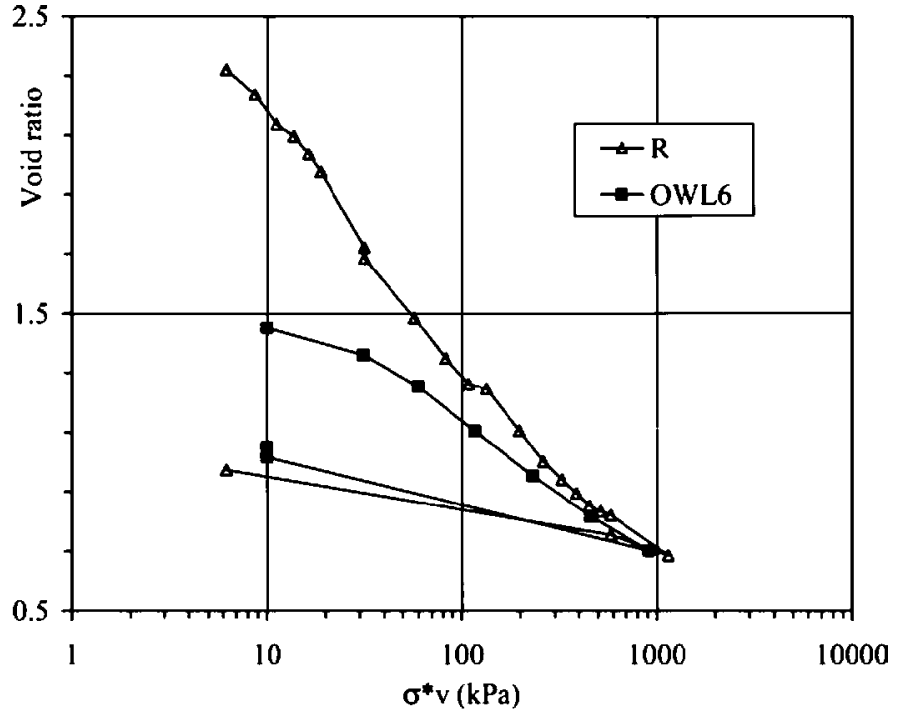

FIG. 9-Comparison of Tests $R$ and OWL6 ( $s=0$ during loading).

OWL6, because they were both conducted under a saturated state. SP1 was compared to Test SDL1, because imposed suction was 20.5 MPa during mechanical loading in both tests. SP2 was compared to SDL5, because a suction of $287.9 \mathrm{MPa}$ was imposed in both tests.

\section{Discussion}

The comparison of the results of Tests OWL6 and R (Fig. 9) shows that the effect of the preparation technique on the mechanical behavior disappeared progressively as the vertical stress tends towards the stress used to compact the OWL6 sample (1000 kPa). The comparison of Tests SP1 and SDL1 (suction of $20.5 \mathrm{MPa}$ ) showed that the preparation technique resulted in the existence of an overconsolidated domain in the case of Test SDL1. When the vertical stress of $1000 \mathrm{kPa}$ was reached in both tests, the influence of the preparation technique seemed to be negligible (Fig. 10). In the case of the tests carried out under a suction of $287.9 \mathrm{MPa}$ 


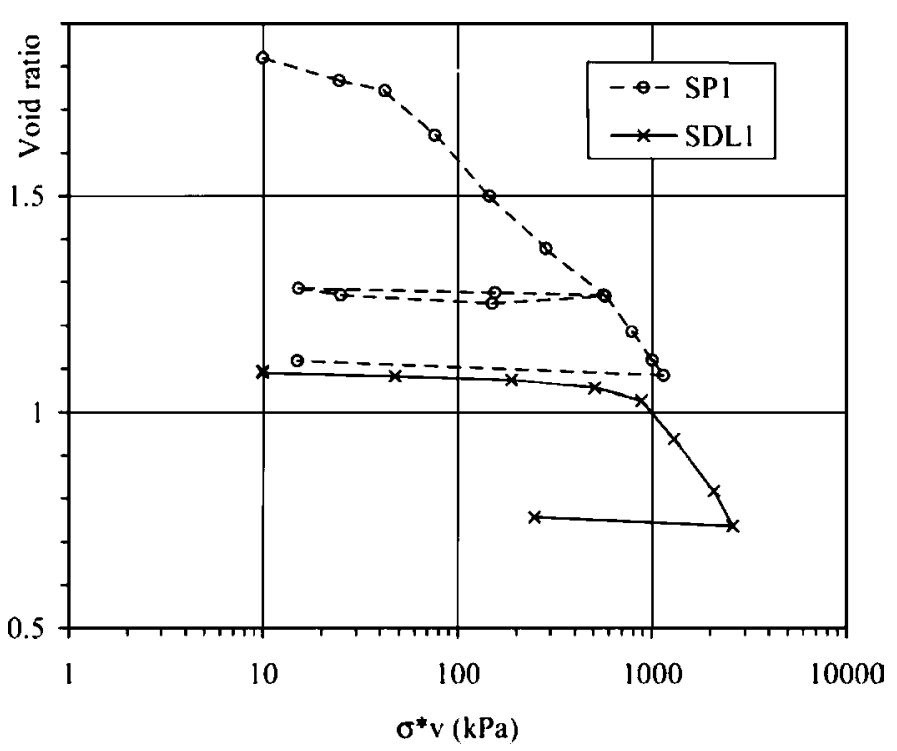

FIG. 10-Comparison of Tests SP1 and SDL1 ( $s=20.5 \mathrm{MPa}$ during loading).

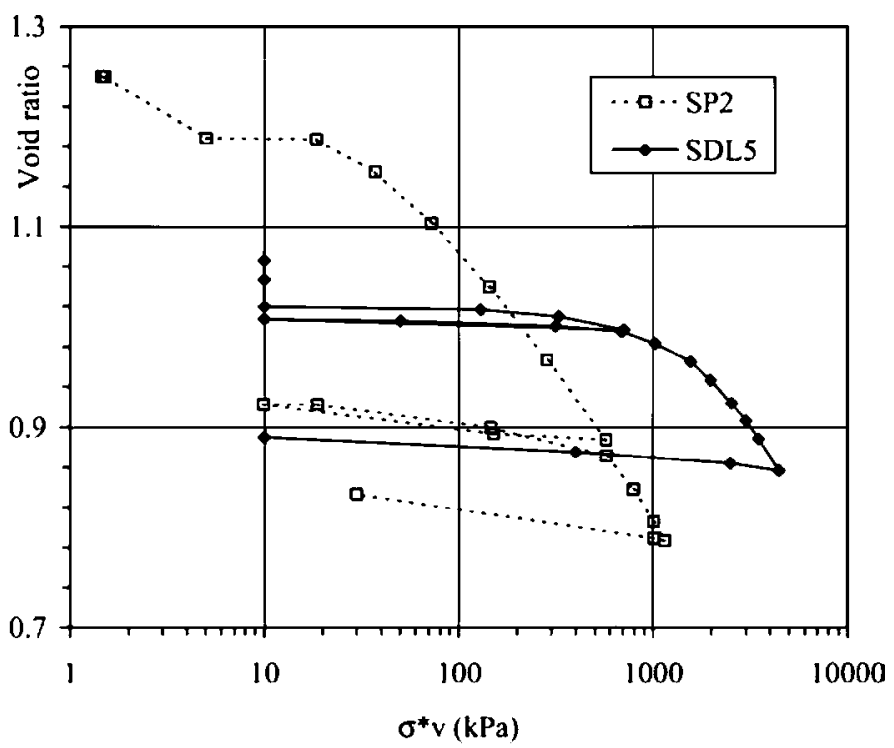

FIG. 11-Comparison of Tests SP2 and SDL5 ( $s=287.9$ MPa during loading).

(Fig. 11), it was noted that the two compressibility curves do not join beyond a vertical net stress of $1000 \mathrm{kPa}$. To explain this point, the whole stress path followed to carry out the Test SDL5 needs to be considered. Sample SDL5 was prepared in the same way as all the compacted samples: a dry mixture was initially wetted to a mass water content of $15 \%$ and then compacted to $1000 \mathrm{kPa}$ (suction of about $20 \mathrm{MPa}$ ). Finally, the sample was then dried up to $287.9 \mathrm{MPa}$ before mechanical loading. Consequently, the SDL5 sample underwent a wetting/drying cycle before the mechanical loading was performed. In comparison, the SP2 sample did not experience any wetting/drying cycle, and this could explain the differences in the observed mechanical behavior.

An important conclusion of the tests conducted on noncompacted samples concerns the variation in $\lambda(s)$ as a function of suction. The $\lambda(s)$ values obtained with noncompacted samples were compared to data obtained on compacted samples (Fig. 12). It appeared that

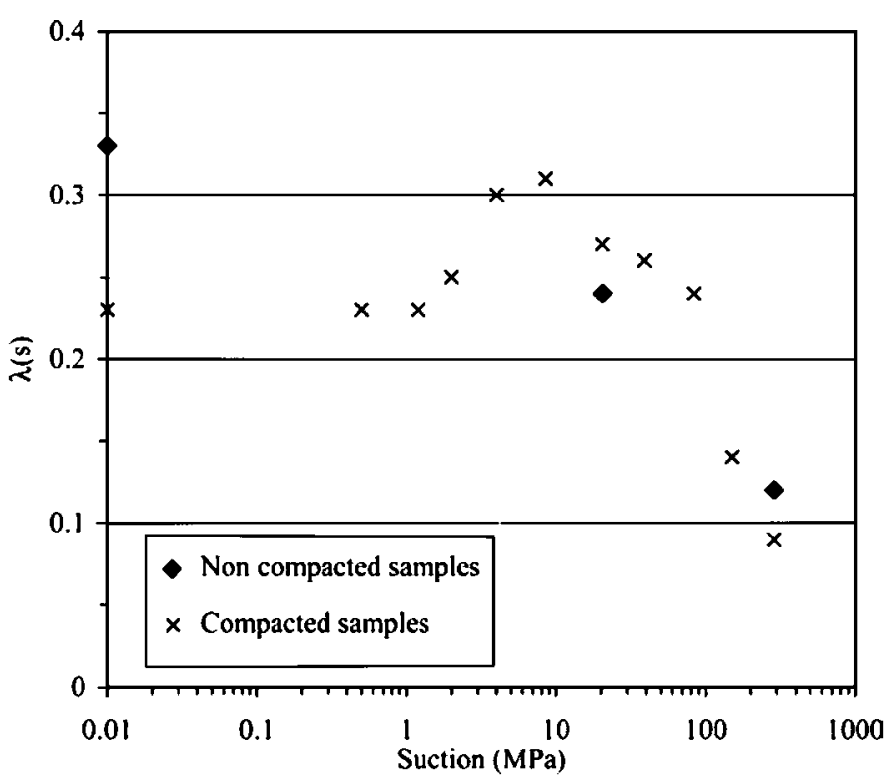

FIG. 12-Influence of the sample preparation method on slope $\lambda(s)$.

for the additional tests, parameter $\lambda(s)$ decreased continuously as suction was increased. Consequently, it could be concluded that the relationship between the mechanical behavior of a compacted swelling soil and suction is directly related to the technique used to prepare the samples. This observation tends to confirm the results of Sivakumar and Wheeler (2000) obtained on a totally different material. Further work should be undertaken to discover the origin of this dependency.

\section{Conclusion}

This paper has presented a study of the hydromechanical behavior of a swelling soil performed in the range of suctions comprised between 0 and around $300 \mathrm{MPa}$. To achieve this study, two types of suction controlled oedometers were used using either the osmotic method or the salt solutions method. In the first section, the conditions for employing each method were defined. It appeared that the use of the salt solutions method should be restricted to suctions above $8.5 \mathrm{MPa}$, due to uncertainties on the $\mathrm{RH}$ value imposed by a given salt. The calibration of the osmotic method was extended up to $8.5 \mathrm{MPa}$. Hence, these two methods can be used complementarily to determine the hydromechanical behavior of a swelling soil over a wide suction range.

The hydromechanical behavior characterization of a compacted swelling material was then presented. The variation of several hydromechanical parameters with the applied suctions was studied. Two kinds of hydromechanical behavior were highlighted as a function of the applied suction. Beyond a suction of $4 \mathrm{MPa}$, the mechanical loading produced a slight increase in the saturation degree, whereas the mass water content was not affected by the mechanical loading. Below $4 \mathrm{MPa}$, the final saturation degree was close to saturation and water was expelled from the sample during the loading. An important result was the variation of the slope $\lambda(s)$ with suction that was not monotonous as the material compressibility was maximum under a suction of $4 \mathrm{MPa}$. This observation differs from most data available in the literature, which show a reduction in this parameter when suction increases. Additional tests have shown that this behavior seems to be related to the preparation technique of the tested samples that controls their initial internal structure. 
This confirmed similar existing data obtained by other authors with nonswelling materials.

Consequently, it could be considered that the mechanical behavior of a material is not a unique function of its composition but also depends on the method used to set it up. This controls its initial structure. Further work will be undertaken to give insight into the relationship between soil structure and the hydromechanical behavior of compacted swelling material.

\section{References}

Al-Mukhtar, M., Qi, Y., Alcover, J. F., and Bergaya, F., 1999, "Oedometric and Water Retention Behavior of Highly Compacted Unsaturated Smectites," Canadian Geotechnical Journal, Vol. 36, pp. 675-684.

Alonso, E. E., Gens, A., and Josa, A., 1990, "A Constitutive Model for Partially Saturated Soils," Géotechnique, Vol. 40, pp. 405430.

Alonso, E. E., Romero, E., Hoffmann, C., and García-Escudero, E., 2001, "Expansive Bentonite/Sand Mixtures in Cyclic Controlled Suction Drying and Wetting," 6th International Workshop on Key Issues in Waste Isolation Research, Paris, France, pp. 513-542.

Coleman, J. D., 1962, "Stress-Strain Relations for Partly Saturated Soils," Géotechnique, Vol. 12, pp. 348-350.

Cuisinier, O., 2002, "Hydromechanical Behavior of Compacted Swelling Soil (in French)," PhD Thesis, Lorraine National Polytechnic Institute, Nancy, France.

Cuisinier, O. and Masrouri, F., 2002, "Study of the Hydromechanical Behaviour of a Swelling Soil Under High Suctions," 3rd International Conference on Unsaturated Soils, Recife, Brazil, Vol. 2, pp. 587-592.

Cuisinier, O. and Masrouri, F., 2001, "Study of the Hydromechanical Behaviour of a Swelling Soil from Low to Very High Suctions," 6th International Workshop on Key Issues in Waste Isolation Research, Paris, France, pp. 61-70.

Delage, P. and Lefebvre, G., 1984, "Study of the Structure of a Sensitive Champlain Clay and of its Evolution During Consolidation," Canadian Geotechnical Journal, Vol. 21, pp. 21-35.

Delage, P., Howat, M. D., and Cui, Y. J., 1998, "The Relationship Between Suction and the Swelling Properties in a Heavily Compacted Swelling Clay," Engineering Geology, Vol. 50, pp. 31-48.

Dueck, A., Börgesson, L., and Wadsö, L., 2001, "Constant Volume Tests with Suction Control Performed on a Swelling Clay," 6th International Workshop on Key Issues in Waste Isolation Research, Paris, France, pp. 83-101.

Escario, V. and Saez, J., 1973, "Measurement of the Properties of Swelling and Collapsing Soils under Controlled Suction," Proceedings, 3rd International Conference on Expansive Soils, Haifa, Israel, pp. 195-200.

Esteban, F. and Saez, J., 1988, "A Device to Measure the Swelling of Rock Samples with Control of Suction Up to Very High Values," ISRM Symposium on Rocks Mechanics and Power Plants, Madrid, Spain, Vol. 2.

Fredlund, D. G. and Morgenstern, N. R, 1977, "Stress State Variables for Unsaturated Soils," Journal of Geotechnical Engineering, Vol. 103, pp. 447-466.
Geiser, F., 1999, "Mechanical Behavior of an Unsaturated SiltExperimental Study and Constitutive Modelling (in French)," $\mathrm{PhD}$ Thesis, Swiss Federal Institute of Technology, Lausanne, Switzerland.

Griffiths, F. J. and Joshi, R. C., 1989, "Change in Pore Size Distribution Due to Consolidation of Clays," Géotechnique, Vol. 39, pp. 159-167.

Guillot, X., Al-Mukhtar, M., Bergaya, F., and Fleureau, J. M., 2002, "Porosity Assessments in a Clay Material (in French)," Comptes Rendus Géoscience, Vol. 332, pp. 105-109.

Guiras-Skandaji, H., 1996, "Deformability of Unsaturated Clay Soils: Experimental and Modeling Study (in French)," $\mathrm{PhD}$ thesis, Lorraine National Polytechnic Institute, Nancy (France).

Kassif, G. and Ben Shalom, A., 1971, "Experimental Relationship Between Swell Pressure and Suction," Géotechnique, Vol. 21, pp. 245-255.

Komine, H. and Ogata, N., 1992, "Swelling Characteristics of Compacted Bentonite," 7th International Conference On Expansive Soils, Dallas, TX, Vol. 1, pp. 216-221.

Lide, D. R. (Ed.), 2002, Handbook of Chemistry and Physics $-82 \mathrm{nd}$ Edition, CRC Press, pp. 15.25-15.26.

Lloret, A., Villar, M. V., Sanchez, M., Gens, A., Pintado, X., and Alonso, E. E., 2003, "Mechanical Behaviour of Heavily Compacted Bentonite Under High Suction Changes," Géotechnique, Vol. 53, pp. 27-40.

Qi, Y., Al-Mukhtar, M., Alcover, J. F., and Bergaya, F., 1996, “Coupling Analysis of Macroscopic and Microscopic Behaviour in Highly Consolidated Na-laponite Clays," Applied Clay Science, Vol. 11, pp. 185-197.

Richards, A., 1935, "Capillary Conduction of Liquids through Porous Medium,” Physics, Vol. 1, pp. 318-333.

Robinet, J. C., Pasquiou, A., Jullien, A., Belanteur, N., and Plas, F., 1997, "Laboratory Experiment on the Thermo-HydroMechanical Behavior of Remolded Swelling and Nonswelling Clays (in French)," Revue Française de Géotechnique, Vol. 81, pp. 53-80.

Romero, E., 1999, "Characterisation and Thermo-Hydro-Mechanical Behaviour of Unsaturated Boom Clay: an Experimental Study," PhD Thesis, Polytechnical University of Catalunya, Barcelona, Spain.

Sivakumar, V. and Wheeler, S. J., 2000, "Influence of Compaction Procedure on the Mechanical Behaviour of an Unsaturated Compacted Clay. Part 1: Wetting and Isotropic Compression," Géotechnique, Vol. 50, pp. 359-368.

Wheeler, S. J. and Sivakumar, V., 1995, "An Elasto-Plastic Critical State Framework for Unsaturated Soil," Géotechnique, Vol. 45, pp. 35-53.

Williams, J. and Shaykewitch, C. F., 1969, "An Evaluation of Polyethylene Glycol (PEG) 6000 and PEG 20000 in the Osmotic Control of Soil Water Matric Potential," Canadian Journal of Soil Science, Vol. 49, pp. 397-401.

Yong, R. N., 1999, "Engineering Geology," Soil Suction and SoilWater Potentials in Swelling Clays in Engineered Clay Barriers, Vol. 54, pp. 3-13.

Zur, B., 1966, "Osmotic Control of the Matric Soil-Water Potential: I. Soil Water System,” Soil Science, Vol. 102, pp. 394-398. 